City University of New York (CUNY) CUNY Academic Works

2009

\title{
Suicide Associated with Military Service
}

Margo R. Genderson

Boston University

Irvin Sam Schonfeld

CUNY Graduate Center

Mark S. Kaplan

Portland State University

Michael J. Lyons

Boston University

\section{How does access to this work benefit you? Let us know!}

More information about this work at: https://academicworks.cuny.edu/gc_pubs/272

Discover additional works at: https://academicworks.cuny.edu

This work is made publicly available by the City University of New York (CUNY).

Contact: AcademicWorks@cuny.edu 


\section{Suicide Associated with Military Service}

\author{
Margo R. Genderson \\ Boston University \\ Irvin Sam Schonfeld \\ The City College of the City \\ University of New York \\ Mark S. Kaplan \\ Portland State University \\ Michael J. Lyons \\ Boston University \\ With the assistance of \\ Jessie Mandle
}

Suicide rates among soldiers and veterans of Operations Iraqi Freedom and Enduring Freedom (OIF/OEF) have been steadily growing since 2004, with sharp increases observed more recently. Suicides in the Army are a growing concern on Capitol Hill and in the media. Last month, the Senate Armed Services Committee held hearings on the growing incidence of suicides across the armed forces (Federal city digest, 2009, March 18). The Associated Press (AP) underlined the increasing suicide rates among Army personnel (Army reports sharp rise in suicides in January, 2009, Feb. 5). According to the AP, there were 64 suicides in 2004, and this number has doubled in 2008, with 128 confirmed deaths and 15 pending investigation. This is the largest number of suicides among active-duty soldiers in the Army observed in the past 28 years (Kuehn, 2009).

\section{Dimensions of the problem}

Another way to look at the trend in Army suicide rates is as follows: the rate was 12.7 per 100,000 in 2005 , 15.3, in 2006, 16.8, in 2007, and 20.2, in 2008 (Dreazen, 2009). Suicide rates in January 2009 were reported to be particularly high, with 7 confirmed deaths and 17 still under investigation. Since the majority of alleged suicides are eventually confirmed, the final count may be close to 24, far exceeding previous months in 2008 and even surpassing the 16 combat deaths in Iraq and Afghanistan that same month. There were 10 confirmed suicides in January 2006, six in January 2007, and five in January 2008, according to the AP. Historically, the risk of suicide in the military tends to be at least $20 \%$ lower than that of the US general population (Eaton et al., 2006). The 2008 suicide rate among active-duty Army personnel, 20.2 per 100000 , exceeds the 2005 rate of 19.5 per
100,000 for demographically matched civilians, the most recent statistic available (Kuehn, 2009).

The suicide rate among war veterans is also higher than among civilians and has been studied empirically. Kang and Bullman (2008) compared suicide risk in a sample of 490,346 veterans who served in OIF/OEF from October 2001 to December 2005 to that of civilians. They found that 144 veterans killed themselves (21.9 individuals per $100,000)$, although the difference in suicide rates between veterans and civilians, controlling for age and sex, did not reach statistical significance. Risk for suicide among veterans in this sample also varied little by military service branches, the Army, Marines, Navy, and Air Force. Former active duty veterans (as opposed to veterans who were in the Reserves or National Guard), however, had a significantly increased risk of suicide compared to civilians (33\% increased risk; 24.7 per 100,000).

Research has also compared suicide rates among wars. There were only two reported suicides during the 1991 Gulf War, although this war only lasted six weeks and cannot be compared to OIF/ OEF (Nelson, 2004). One study compared suicidality, an index derived from the severity of suicide attempts, be-

tween 320 World War II veterans, 199 Korean War veterans, and 4,619 Vietnam War veterans seeking treatment at VA facilities (Fontana \& Rosenheck, 1994). Although more suicidality was observed in Korean veterans compared to Vietnam veterans, the difference did not reach statistical significance, and veterans from both of these wars were more suicidal than WW II veterans. There was a significant relation between traumatic experiences, especially killing another person, and psychological symptoms in all three groups, although the relation between trauma and suicidality was only significant among Vietnam veterans. Fontana and Rosenheck suggested that differences in symptomatology and suicidality may be related to differences in the degree of popular support for each war. For example, compared to the Korean and Vietnam War veterans, WW II veterans were treated more as heroes after the war. Alternatively, WW II veterans may have underreported symptoms as a result of the greater stigma attached to mental disorder in that era (Fontana \& Rosenheck, 1994). In addition, military branch, service era, nature of service (conscripted or voluntary), and combat exposure may all affect the risk of suicide (MacLean \& Elder, 2007).

Firearms are the most common method used in military suicide fatalities. According to Allen et al. (2005), $72 \%$ of Army suicides involved firearms, compared to $52 \%$ in the general population (AAS, 2008). Research shows that the suicide method that is most available and acceptable will be used most often. Although affective disorder (e.g., major depression, bipolar disorder) and substance abuse increase the risk of suicidal behavior, the widespread availability of firearms in the military increases the degree of lethality of suicide attempts (Goldsmith, 2001).

To further appreciate the dimension of the problem, consider a RAND Corporation study of a representative sample of more than 1900 previously deployed OIF/OEF personnel from all branches of the military (Tanielian \& Jaycox, 2008). The interview methodology yielded probable diagnoses of posttraumatic stress disorder (PTSD), major depressive disorder (MDD), and traumatic brain injury. RAND investigators estimated that in the 30 days prior to the interview, approximately $14 \%$ were currently affected with PTSD, $14 \%$, with MDD, and $19.5 \%$, with traumatic brain injury. Each of the three disorders is a risk factor for suicide. Only about half of those with a diagnosis of MDD or PTSD received care, and the care was often less than optimal. In a population-based study antedating OIF/ OEF, Kaplan et al. (2007) found that male veterans were twice as likely as male non-veterans to die by suicide, controlling for other risk factors (too few female veterans died by suicide to be included in the analyses). Kang and Bullman reported that veterans diagnosed with a mental disorder had a $77 \%$ increased risk of suicide compared to civilians.

A study of 103,788 OEF/OIF veterans seen at VA health care facilities between 2001 and 2005 (Seal et al., 2007) found that $25 \%$ of veterans were diagnosed with a mental disorder and $31 \%$ received a mental health diagnosis and/ or demonstrated psychosocial problems as indicated by a V-code diagnosis. The most prevalent diagnosis was PTSD, which was found in $13 \%$ of the sample, a rate much higher than in the US general population (3.5\%) (Kessler et al., 2005). Of the ... (Continued on page 6)
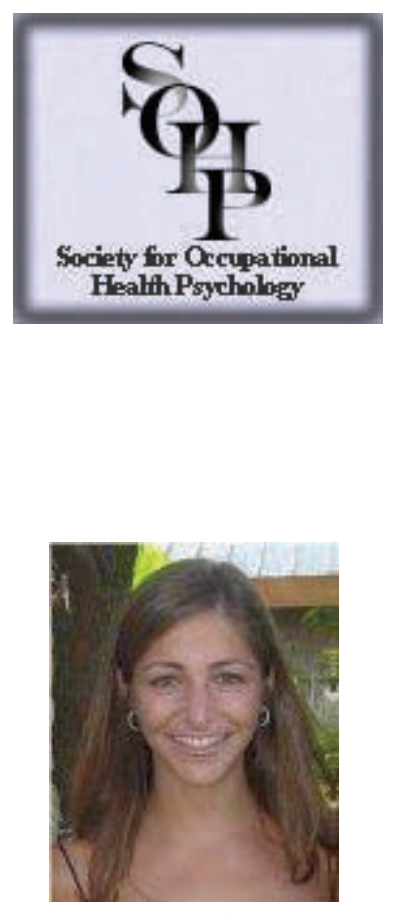

Margo Genderson

Boston University

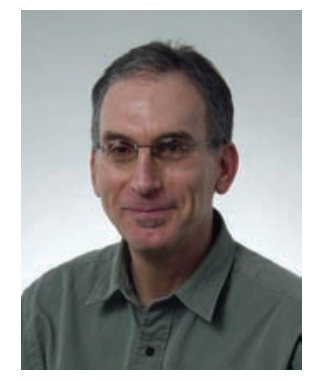

Mark Kaplan

Portland State University

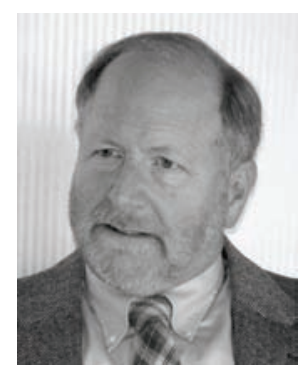

Michael Lyons

Boston University 


\section{Suicide Associated with Military Service (cont'd)}

(Continued from page 5) ... veterans diagnosed with a mental disorder, $56 \%$ of individuals received 2 or more diagnoses. Younger veterans (age 18-24 years) were at an increased risk for developing mental disorders compared with veterans 40 years or older. The difference in risk may be related to the fact that younger veterans had more combat exposure.

\section{Prevention}

With the rate of suicide currently increasing among individuals in the military, an emphasis must be placed on identifying risk factors and developing effective preventative programs. According to the AP, Army Secretary Pete Geren acknowledged that officials cannot explain the recent sharp increase in suicide rates, although veterans suffering from problems in personal relationships, legal or financial difficulties, and problems on the job are at increased risk for attempting suicide. Multiple deployments and extended lengths of deployment may also be contributing factors.

Efforts that focus on treating mental disorders, therefore, may help to decrease the suicide rate among veterans. Knox and colleagues (2003) examined the effects of exposure to a suicide prevention program, which focused on removing the stigma of seeking mental health treatment, ensuring confidentiality in treatment, strengthening social support, promoting effective coping skills, enhancing understanding of mental health, and changing policies and social norms. This program was developed in response to the increased suicide rate in the Air Force from 19901995. The Vice Chief of Staff commissioned a team of experts to investigate suicide risk and recommend a prevention strategy. The study included 5,260,292 active duty personnel in the US Air Force between 1990 and 2002. Individuals who served from 1997-2002 were exposed to the program, and suicide rates among these Air Force personnel were compared to the "unexposed" cohort who served from 1990-1996. The program was associated with a $33 \%$ reduction in the risk for suicide. Potential confounders such as age, race, sex, marital status, and mental health diagnostic status could not explain the differences in suicide rates between the two time periods. Although the intervention was successful in re- ducing the risk of suicide in the Air Force, it is not clear if the program would work in other branches of the armed forces with different sociodemographic profiles.

Perceived stigmatization and other barriers to mental health care are still a concern among veterans. Only 23 to $40 \%$ of veterans returning from Iraq and Afghanistan who demonstrated symptoms of a mental disorder sought care, and these individuals were twice as likely to report concern about stigmatization and other barriers to receiving care compared to individuals in the general population (Hoge et al., 2004). On the other hand, more veterans of OIF/OEF have enrolled in VA health care (approximately $29 \%$ ) compared to Vietnam veterans $(10 \%$ ) (Seal et al., 2007). Veterans are accessing care very quickly, with an average of less than 3 months from leaving the military to first visit. The average time from first visit to mental health diagnosis is only 13 days. The increased percentage of veterans seeking treatment and the relative speed with which they are being assessed and diagnosed opens the door to early intervention for treating mental illness. Based on the success of previous programs (e.g., Knox et al. 2003), more efforts should focus on reducing the stigma associated with seeking mental health treatment, which may aid in suicide prevention efforts.

Another preventative approach that has been empirically studied includes the use of assessment instruments to identify individuals who are at elevated risk of suicide. For example, the Interpersonal-Psychological Survey (IPS) is designed to assess an individual's capacity for self-harm, perceived burdensomeness, and thwarted belongingness, three factors that are associated with suicide risk. By investigating postmortem files, one group of investigators retrospectively obtained IPS scores of US Air Force personnel who had committed suicide (Nademin et al., 2008). These scores were compared to IPS scores of active duty Air Force personnel, and significant differences were found between groups. The IPS, therefore, may be a useful predictor of suicide risk and could be used to target early intervention efforts in the US military. Retrospectively assessing IPS scores for individuals who have committed suicide, however, may lead to biases and other validity problems.

The military has taken steps to respond to the seriousness of the current situation and implement preventative programs. For example, the AP reported that, in order to raise awareness and monitor suicide rates, Army officials are releasing month-to-month data on suicides, which has never been done in the past. In addition, the Army has developed programs to provide soldiers with more support. The BATTLEMIND program, begun in 2006, provides soldiers with skills to help cope with stress encountered during deployment and helps soldiers and their families readjust after returning from overseas (Kuehn, 2009, Thomas, 2008; also see https://www.battlemind.army.mil/). Another program developed by the Army provides troops with education about suicidal behaviors with the hope of increasing awareness in order to enable soldiers to recognize suicide risk in others and intervene (Army reports sharp rise in suicides in January, 2009, Feb. 5). Beginning in October 2008, The National Institute of Mental Health and the Army are collaborating on a fiveyear prospective study of suicide among soldiers (Kuehn, 2009). The study aims to assess soldiers at multiple stages during their service and after separation from the Army in order to identify susceptibility and resiliency factors visà-vis suicidal thoughts and behaviors. Factors such as differences in soldiers vulnerability to the stress of extended deployments, physiological responses to stress, ability to readjust to life at home, alcohol and drug use, genetic predisposition, interpersonal factors, and stressful life events will be explored. This study will be a contribution to the understanding of risk factors and precipitating circumstances for suicide and may lead to more effective interventions.

The men and women in the United States military have made great sacrifices for this country, and we owe them our full support and gratitude. This includes providing our service men and women with effective mental health care to help them cope with long and taxing war-zone deployments. The care these men and women deserve must continue on seamlessly through the transition from active duty to the home front and civilian life.

(Continued on page 7 )

\section{"Suicides in the Army are a growing concern on Capitol Hill and in the media."}

"There was a significant relation between traumatic experiences, especially killing another person, and psychological symptoms." 


\section{Suicide Associated with Military Service (cont'd)}

\section{References}

Allen, J.P., Cross, G., \& Swanner J. (2005). Suicide in the Army: A review of current information. Military Medicine, 170, 580 $-584$.

American Association of Suicidology. U.S.A suicide: 2005 official final data. http://www.suicidology.org/web/quest/statsand-tools/statistics. Accessed April 2, 2009.

Army reports sharp rise in suicides in January. (2009, February 5). The Wall Street Journal.

Dreazen, Y. J. (2009, March 28). The military: A general's personal battle. The Wall Street Journal, W1.

Eaton, K.M., Messer, S.C., Garvey Wilson, A.L., \& Hoge, C.W. (2006). Strengthening the validity of population-based suicide rate comparisons: An illustration using U.S. military and civilian data. Suicide and Life Threatening Behavior, 36, 182-191.

Federal city digest. (2009, March 18). Washington Post, A11

Fontana, A., \& Rosenheck, R. (1994). Traumatic war stressors and psychiatric symptoms among World War II, Korean, and Vietnam War veterans. Psychology and Aging, 9, 27-33.

Goldsmith, S.K. (2001). Risk factors for suicide: A summary of a workshop. Washington, DC: National Academy Press.

Hoge, C.W., Castro, C.A., Messer, S.C., McGurk, D., Cotting, D.I., \& Koffman, R.L. (2004). Combat duty in Iraq and Afghanistan, mental health problems, and barriers to care. The New England Journal of Medicine, 351, 13-22.

Kang, H.K., \& Bullman, T.A. (2009). Risk of suicide among US veterans after returning from the Iraq or Afghanistan war zones. JAMA, $300(6), 652-653$.

Kaplan, M.S., Huguet, N., McFarland, B.H., \& Newsom, J.T. (2007). Suicide among male veterans: A prospective populationbased study. Journal of Epidemiology and Community Health, 61, 619-624.

Kessler, R.C., Chiu, W.T., Demier, O., \& Walters, E.E. (2005). Prevalence, severity, andcomorbidity of 12-month DSM-IV disorders in the National Comorbidity Survey Replication. Archives of General Psychiatry, 62, 617-627.

Knox, K.L., Litts, D.A., Talcott, G.W., Feig, J.C., \& Caine, E.D. (2003). Risk of suicide and related adverse outcomes after exposure to a suicide prevention program in the US Air Force: Cohort study. BMJ, 327, 1376-1380.

Kuehn, B.M. (2009). Soldier suicide rates continue to rise. JAMA, 301, 1111-1113.

MacLean A., \& Elder, G.H., Jr. (2007). Military service in the life course. Annual Review of Sociology, 33, 175-196.

Nademin, E., Jobes, D.A., Pflanz, S.E., Jacoby, A.M., Ghahrananlou-Holloway, M. Campise, R., et al. (2008). An investigation of interpersonal-psychological variables in Air Force suicides: A controlled-comparison study. Archives of Suicide Research, 12, 309-326.

Nelson, R. (2004). Suicide rates rise among soldiers in Iraq. The Lancet, 363, 300.

Seal, K.H., Bertenthal, D., Miner, C.R., Sen, S., \& Marmar, C. (2007). Bringing the war back home: Mental health disorders among 103,788 US veterans returning from Iraq and Afghanistan seen at Department of Veterans Affairs facilities. Archives of Internal Medicine, 167, 476-482.

Tanielian, T., \& Jaycox, L. H. (2008). Invisible wounds of war: Psychological and cognitive injuries, their consequences, and services to assist recovery. Santa Monica, CA: RAND Corp.

Thomas, J. L. (2008). OHP Research and Practice in the US Army: Mental Health Advisory Teams. Newsletter of the Society for Occupational Health Psychology, 4, 4-5. http://sohp.psy.uconn.edu/SOHPNewsletterV4October2008.pdf 